\title{
Erratum to: Penman-Monteith approaches for estimating crop evapotranspiration in screenhouses-a case study with table-grape
}

\author{
Moran Pirkner • Uri Dicken • Josef Tanny
}

Published online: 1 June 2013

(C) ISB 2013

Erratum to: Int J Biometeorol

DOI 10.1007/s00484-013-0653-z

This figure replaces Fig. 4 in the original article. 


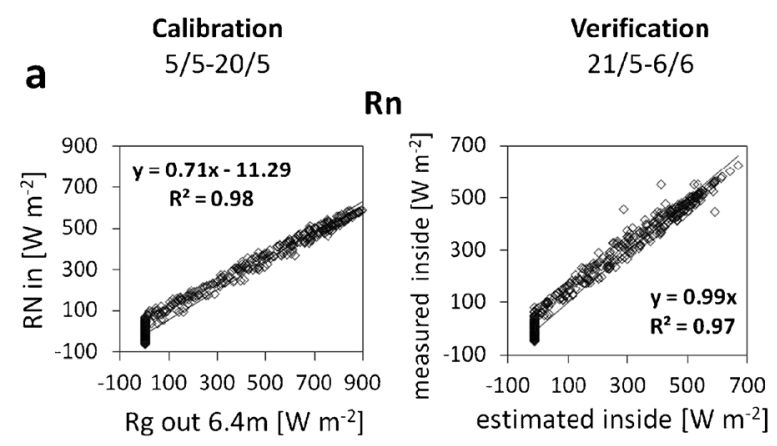

b

Temperature
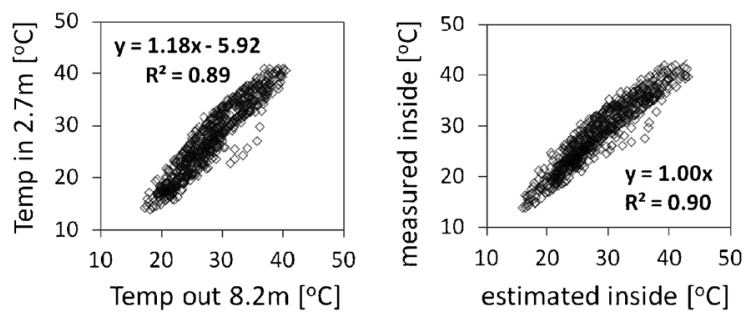

C

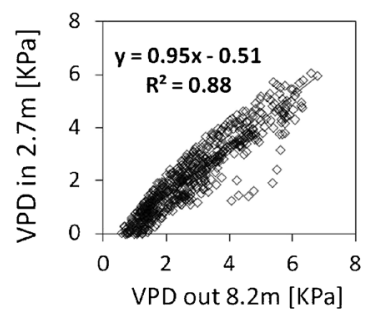

VPD

d
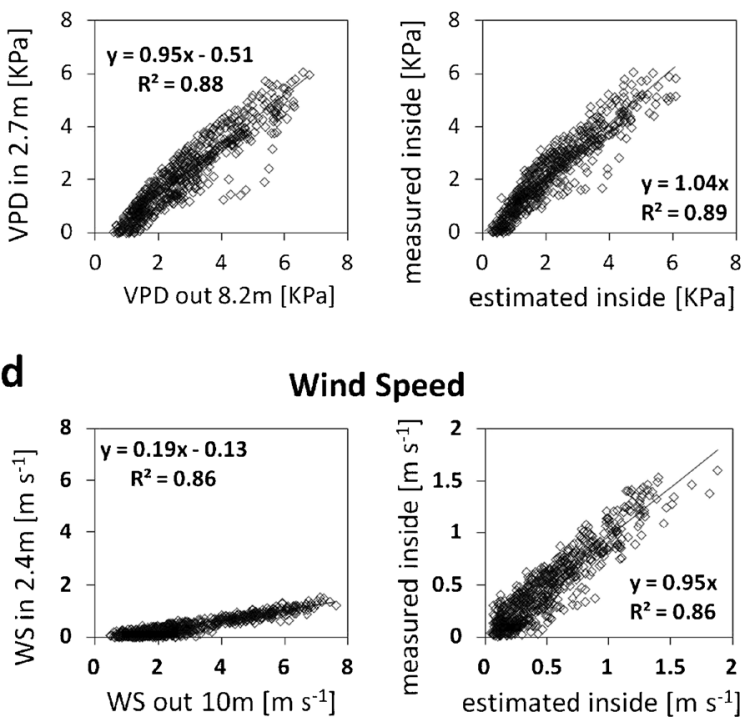

Wind Speed

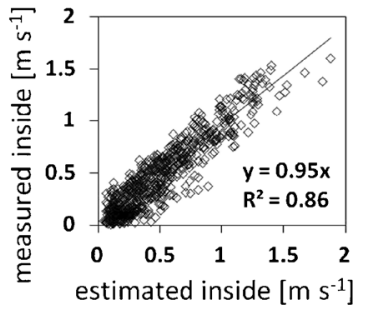

e

\section{Leaf Resistance $\left(r_{1}\right)$}
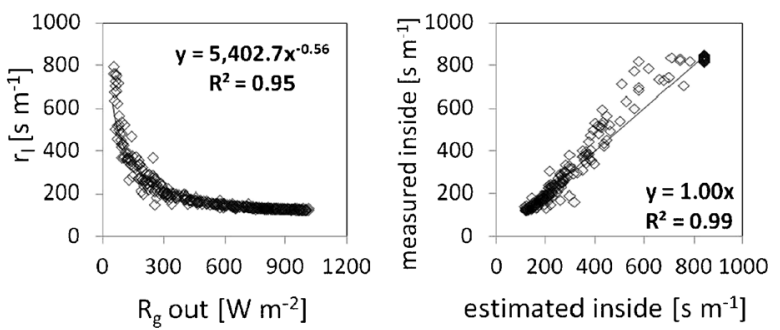

Fig. 4 Calibration (left-hand panels): dependence of the measured inside variables on external data during 14 days, and their regression equations. Verification (righ-thand panels): linear regressions between the predicted values calculated with the calibration equations (from the left-hand panels) and the measured values during the 14 verification days. a Net radiation; b Temperature; c VPD; $\mathbf{d}$ Wind speed; e Leaf resistance 